\title{
Prospek dan Nilai Tambah Pengolahan Mangga (mangifera indica, 1.) Varietas Gedong Gincu Menjadi Kerupuk Pada Home Industri Di Kabupaten Indramayu
}

\author{
Sulayman Rivai ${ }^{1}$, Entus Hikmana ${ }^{2}$, Karto $^{3}$ \\ 1,2,3,4 Program Studi Agribisnis, Fakultas Pertanian Universitas Wiralodra, \\ Email: rivai@gmail.com¹, entushikmana@gmail.com², karto@gmail.com ${ }^{3}$
}

\begin{abstract}
ABSTRAK
Tujuan dari penelitian ini adalah untuk menganalisa nilai tambah pengolahan mangga (Mangifera indica, L.) Varietas Gedong Gincu menjadi kerupuk secara rinci untuk mengetahui (1) besarnya nilai tambah yang dihasilkan dari pengolahan buah mangga menjadi kerupuk pada home Industri Libna Food (2) mengetahui rasio nilai tambah yang dihasilkan dari pengolahan buah mangga menjadi kerupuk pada home Industri Libna Food.

Metode yang digunakan adalah metode survai, dan menggunakan desain survai deskriptif. Untuk penelitian ini tidak di lakukan pengambilan sampel dari populasi karena populasi home industrikerupuk dengan bahan baku mangga hanya satu orang, yaitu Home industry Libna Food satu satunya Home industry yang memproduksi kerupuk mangga berada di Desa Jatisura Kecamatan Cikedung Kabupaten Indramayu.

Berdasarkan hasil penelitian ini usaha pengolahan kerupuk mangga di Home industry Libna Food Desa Jatisura Kecamatan Cikedung Kabupaten Indramayu Tahun 2018. Home industry Libna Food memproduksi kerupuk mangga dengan 1 kemasan, yaitu kemasan yang berisi 250 gram. Dengan nilai tambahnya Rp.10.408 untuk kemasan 250 gram dengan rasio nilai tambahnya sebesar $41.63 \%$ dalam satu kali proses produksi.
\end{abstract}

Kata Kunci : Home industri libna food, Nilai tambah, Kerupuk

\section{I.PENDAHULUAN}

Agroindustri memiliki peranan yang sangat penting dalam pembangunan pertanian.Hal ini dapat dilihat dari kontribusinya dalam hal meningkatkan pendapatan pelaku agribisnis, menyerap tenaga kerja, meningkatkan perolehan devisa, dan mendorong tumbuhnya industri lain. Meskipun peranan agroindustri sangat penting, pembangunan agroindustri masih dihadapkan pada berbagai tantangan. Terdapat beberapa permasalahan yang dihadapi agroindustri dalam negeri, antara lain: 1) Kurang tersedianya bahan baku yang cukup dan kontinu; 2) Kurang nyatanya peran agroindustri di pedesaan karena masih berkonsentrasinya agroindustri di perkotaan; 3) Kurang konsistennya kebijakan pemerintah terhadap agroindustri; 4) Kurangnya fasilitas permodalan (perkreditan) dan kalaupun ada prosedurnya amat ketat; 5) Keterbatasan pasar; 6) Lemahnya infrastruktur; 7) Kurangnya perhatian terhadap penelitian dan pengembangan; 8) Lemahnya keterkaitan industri hulu dan hilir; 9) Kualitas produksi dan prosesing yang belum mampu bersaing; 10) Lemahnya entrepreneurship (Soekartawi, 2000). Mangga adalah buah bernilai ekonomi tinggi dan merupakan bahan makanan penting setelah pisang bagi masyarakat di daerah beriklim tropis.

Kabupaten Indramayu mempunyai potensi yang baik untuk produksi mangga, dan di kecamatan Cikedung mempunyai potensi untuk produksi mangga gedong gincu, luas panen tanaman mangga, dan produktivitas tanaman manga. 
Tabel 1. Luas Panen, Produksi Mangga,dan Produktivitas Mangga di Kabupaten Indramayu Tahun 20122016

\begin{tabular}{cccc}
\hline Tahun & $\begin{array}{c}\text { LuasPanen } \\
\text { (pohon) }\end{array}$ & JumlahProduksiMangga(Kw) & Produktivitas (Kw/Pohon) \\
\hline 2012 & 577.865 & 685.177 & 1,19 \\
2013 & 660.147 & 847.878 & 1,28 \\
2014 & 1.153 .176 & 1.156 .366 & 1.00 \\
2015 & 492.494 & 712.818 & 1,45 \\
2016 & 575.234 & 1.436 .148 & 2,50 \\
\hline
\end{tabular}

Sumber : Badan Pusat Statistik (2017)

Namun karena hasil produksi buah mangga gedong gincu melimpah pada saat musim panen dan membuat harganya turun serta usaha agroindustri olahan mangga gedong gincu masih bersifat sederhana. Peminat produk olahan mangga di Indramayu sangat banyak, sehingga perlu dilakukan pemasyarakatan dan promosi produksi kepada masyarakat guna mengetahui manfaat dan cara pengolahan buah mangga untuk meningkatkan perekonomian masyarakat sekitar

\section{METODE PENELITIAN}

Metode penelitian yang digunakan dalam penelitian ini adalah metode survei deskriptif, yaitu penyelidikan yang diadakan untuk memperoleh fakta-fakta dari gejala-gejala yang ada dan mencari keterangan-keterangan secara faktual, baik tentang institusi sosial, ekonomi, atau politik dari suatu kelompok ataupun suatu daerah.Nazir (1988), menyatakan bahwa metode deskriptif merupakan suatu metode dalam meneliti status sekelompok manusia, suatu objek, suatu set kondisi, suatu sistem pemikiran ataupun suatu kelas peristiwa pada masa sekarang. Berdasarkan pernyataan tersebut di atas metode survei dilakukan untuk melihat fenomena secara faktual terhadap fenomena yang akan diselidiki dan metode deskriptif digunakan untuk menggambarkan keadaan saat ini meliputi karakteristik responden dan keadaan sosial ekonomi.

\section{HASIL DAN PEMBAHASAN}

\section{Sistem Produksi Usaha Industri Rumah Tangga Libna Food}

Dalam satu kali proses produksi dilakukan selama dua hari dengan mengolah $10 \mathrm{Kg}$ buah Mangga gedong gincu dan menghasilkan 55 bungkus kerupuk mangga berukuran 250 gram dan akan terjual habis sekitar 1 bulan kedepan dan melakukan kegiatan proses produksi berikutnya.

\section{Tenaga Kerja}

Industri Rumah Tangga Libna Food dalam perekrutan tenaga kerja tidak ada persyaratan khusus yang diberikan oleh pemilik usaha, yang menjadi acuan utama yaitu ketekunan dan keuletan yang dimiliki oleh calon pekerja. Sebelum melakukan pekerjaan, tenaga kerja ini harus mengikuti pelatihan terlebih dahulu agar bisa memahami proses pekerjaan yang akan dilakukan. Proses pelatihan dilakukan pada hari pertama, hal ini dilakukan dengan tujuan agar calon tenaga kerja dapat melakukan pekerjaan dengan baik. Umumnya calon pekerja yang mengikuti proses pelatihan ini bisa melakuan pekerjaan sesuai dengan apa yang diinginkan oleh pemilik usaha.Tenaga kerja yang terdapat pada Industri Rumah Tangga Libna Food berasal dari Desa Jatisura Kecamatan Cikedung Kabupaten Indramayu. Tenaga yang dipekerjakan oleh Industri Rumah Tangga Libna Food dalam produksi kerupuk mangga membutuhkan empat tenaga kerja, yang mana tenaga kerja tersebut telah berpengalaman untuk memproduksi kerupuk mangga, dalam proses produksinya keempat tenaga kerja tersebut dibagi menjadi dua kelompok. 
Kelompok pertama melakukan pekerjaan pengupasan, pencucian, pemotongan, dan pengemasan, kelompok kedua yaitu melakukan pekerjaan pemasakan. Pembagian upah tenaga kerja dapat dilihat pada Tabel sebagai berikut:

Tabel 2.Upah Tenaga Kerja Pengolahan Kerupuk Mangga Industri Rumah Tangga Libna Food

\begin{tabular}{llrcr}
\hline No & Jenis Kegiatan Produksi & $\begin{array}{l}\text { Jumlah } \\
\text { Tenaga } \\
\text { Kerja }\end{array}$ & $\begin{array}{l}\text { Upah } \\
\text { (Rp/Hari) }\end{array}$ & $\begin{array}{l}\text { Jumlah } \\
\text { (Rp/Produksi) }\end{array}$ \\
\hline $1 \quad$ Pengupasan, Pencucian & 1 & 20.000 & 40.000 \\
2 & Pemotongan Pengemasan & 1 & 20.000 & 40.000 \\
$3 \quad$ Pemasakan & 1 & 20.000 & 40.000 \\
$4 \quad$ Pengemasan & 1 & 20.000 & 40.000 \\
Jumlah & & & $\mathbf{1 6 0 . 0 0 0}$ \\
Rata-rata & & & $\mathbf{4 0 . 0 0 0}$ \\
\hline
\end{tabular}

Sumber : Data Primer (diolah) Tahun 2018

\section{Sumbangan Input Lain}

Sumbangan input lain merupakan pembagian total sumbangan input lain dengan jumlah bahan baku yang digunakan. Dalam proses pengolahan kerupuk mangga tentunya bahan baku utamanya adalah buah mangga yang telah matang, tidak busuk. Proses pembuatan kerupuk mangga juga membutuhkan bahan penolong atau sumbangan input lain seperti bahan bakar, gula pasir, dan tepung terigu. Sumbangan input lain pada pengolahan kerupuk mangga di Industri rumah Tangga Libna Food dapat dilihat pada Tabel 3 .

Tabel 3. Sumbangan Input Lain Pada Pengolahan Kerupuk Mangga di Industri Rumah Tangga Libna Food per Siklus Produksi.

\begin{tabular}{llr} 
No & Uraian & Kemasan 250 gram (25 kemasan) \\
\hline 1 & Bahan Penolong & 136.500 \\
2 & Bahan Bakar (Gas) & 22.000 \\
3 & Plastik kemasan, pita dan label & 30.000 \\
4 & Listrik & 6.667 \\
5 & Air & 1.333 \\
6 & Penyusutan Peralatan & 1.525 \\
7 & PBB & 55 \\
\hline Total Per Produksi & $\mathbf{2 2 9 . 5 8 1}$ \\
\hline Total Per Input Produksi & $\mathbf{3 . 6 0 1}$ \\
\hline $\mathbf{5 5}$ Kemasan)
\end{tabular}

Sumber : Data Primer (diolah) Tahun 2018

\section{Bahan Penolong}

Pada pengolahan kerupuk mangga, bahan penolong yang digunakan berupa gula dan tepung terigu. Bahan-bahan tersebut berfungsi sebagai penambah cita rasa, tekstur dan pengawet makanan alami agar kerupuk mangga bisa tahan lebih lama. Selengkapnya dapat dilihat pada Tabel 4. 
Tabel 4 . Penggunaan Bahan Penolong Pengolahan Kerupuk Mangga 250 Gram per Siklus Produksi.

\begin{tabular}{llcrrr}
\hline No & Unsur Bahan & Jumlah & Satuan & Harga(Rp) & \multicolumn{1}{c}{ Jumlah (Rp) } \\
\hline 1. & Gula Pasir & 7 & $\mathrm{Kg}$ & 13.000 & 91.000 \\
2. & Tepung Terigu & 7 & $\mathrm{Kg}$ & 7.000 & 45.500 \\
\hline \multicolumn{7}{c}{ Jumlah } & & $\mathbf{1 3 6 . 5 0 0}$ \\
\hline
\end{tabular}

Sumber : Data Primer (diolah) Tahun 2018

\section{Bahan Bakar (Gas)}

Pada pengolahan kerupuk mangga ini membutuh bahan bakar berupa gas untu menggoreng kerupuk yang sudah kering. Untuk satu kali produksi membutuhkan 1 tabung gas $3 \mathrm{Kg}$ seharga Rp 22.000.

\section{Tenaga Listrik dan Air}

Ketersediaan listrik dan air sangat dibutuhkan dalam memproduksi kerupuk mangga. Biaya listrik termasuk biaya yang harus dikeluarkan untuk penerangan pada saat proses pemilihan buah mangga dan pengupasannya, dikarenakan proses pengupasan dan pemilihan buah mangga dilakukan pada saat pagi hari sekitar pukul 06.30 WIB. Penggunaan listrik pada pengolahan kerupuk mangga kemasan 250 gram Rp. 6667/produksi. Sedangkan untuk penggunaan air pada pengolahan kerupuk mangga untuk kemasan 250 gram Rp. 1333/Produksi. Penggunaan air ini untuk mencuci buah mangga yang telah dikupas dari kulitnya.

\section{Penyusutan Alat}

Penyusutan peralatan merupakan salah satu beban biaya peralatan akibat penggunaan alat dalam proses produksi. Penyusutan peralatan menjadi beban pengusaha sehingga harus diperhitungkan di dalam sumbangan input lain.

Tabel 5. Rincian Biaya Penyusutan Peralatan Dalam Satu Kali Proses Produksi.

\begin{tabular}{clcrcr}
\hline No. & Komponen Biaya & $\begin{array}{c}\text { Jumlah } \\
\text { Fisik } \\
\text { (Satuan) }\end{array}$ & $\begin{array}{c}\text { Jumlah Biaya } \\
\text { (Rp) }\end{array}$ & $\begin{array}{c}\text { Umur } \\
\text { Ekonomis } \\
\text { (Tahun) }\end{array}$ & $\begin{array}{c}\text { Nilai Penyusutan } \\
\text { (Rp/Hari) }\end{array}$ \\
\hline 1. & Pisau & 2 & 8.000 & 1 & 21,92 \\
2. & Ember Sedang & 2 & 14.000 & 1 & 57,53 \\
3. & Spatula & 1 & 6.000 & 1 & 8,22 \\
4. & Nampan & 3 & 27.000 & 1 & 110,96 \\
5. & Peniris & 2 & 5.000 & 1 & 13,30 \\
6. & Blender & 1 & 120.000 & 3 & 54,79 \\
7. & Wajan & 1 & 25.000 & 1 & 34.25 \\
8 & Kompor & 1 & 125.000 & 3 & 57.08 \\
9 & Panci & 1 & 55.000 & 1 & 75.34 \\
10 & Lemari Es & 1 & 1.200 .000 & 5 & 328.77 \\
\hline JUMLAH & $\mathbf{1 6}$ & $\mathbf{1 . 6 8 0 . 0 0 0}$ & $\mathbf{1 8}$ & $\mathbf{7 6 2 . 5 6}$ \\
\hline
\end{tabular}

Sumber : Data Primer (diolah) Tahun 2018.

\section{Produksi dan Nilai Penerimaan Kerupuk Mangga}

Produksi adalah suatu kegiatan yang dilakukan dengan tujuan untuk merubah bahan baku menjadi suatu produk yang berbeda dari bentuk semula. Produksi merupakan pendapatan kotor dalam bentuk fisik dari suatu proses produksi. Sedangkan nilai penerimaan 
yaitu pendapatan kotor yang diperoleh dengan cara mengalikan harga jual dengan banyaknya produksi. Produksi dan penerimaan dapat dilihat pada Tabel berikut ini :

Tabel 6. Rincian Produksi, Jumlah Bungkus, Harga Jual dan Penerimaan kerupuk Mangga per Siklus Produksi di Industri rumah Tangga Libna Food.

\begin{tabular}{llcccr}
\hline No. & Variasi Berat & $\begin{array}{c}\text { Bahan } \\
\text { Baku } \\
(\text { Kg) }\end{array}$ & $\begin{array}{c}\text { Jumlah } \\
\text { Kerupuk } \\
\text { (Kemasan) }\end{array}$ & $\begin{array}{c}\text { Harga Jual } \\
\text { (Rp/Kemasan) }\end{array}$ & $\begin{array}{c}\text { Penerimaan } \\
\text { (Rp/ Produksi) }\end{array}$ \\
\hline 1. & Berat 250 Gram & 10 & 55 & 5.000 & 275.000 \\
\hline & Jumlah & $\mathbf{1 0}$ & $\mathbf{5 5}$ & & $\mathbf{2 7 5 . 0 0 0}$ \\
\hline
\end{tabular}

Sumber : Data Primer (diolah) Tahun 2018

Tabel diatas menunjukkan bahwa Industri rumah Tangga Libna Food memproduksi bahan baku sebanyak $10 \mathrm{~kg}$ yang menghasilkan $13.5 \mathrm{~kg}$ kerupuk mangga. Untuk pengemasan kerupuk mangga mempunyai satu Variasi berat yaitu 250 gram yang menghasilkan kemasan 55 dan mempunyai harga jual sebesar Rp 5000. Industri Rumah Tangga Libna Food sendiri dalam satu kali produksi mendapatkan penerimaan sebesar Rp 275.000 untuk kerupuk mangga dengan variasi berat 250 gram.

\section{Analisis Nilai Tambah Kerupuk Mangga}

Nilai tambah merupakan selisih pertambahan antara nilai produk olahan dengan biaya. Analisis nilai tambah dihitung untuk mengetahui pertambahan nilai buah mangga menjadi Kerupuk mangga, untuk menghitung nilai tambah kerupuk mangga tersebut digunakan analisis nilai tambah dengan pendekatan struktur produksi Metode Hayami. Hasil analisis nilai tambah Kerupuk mangga gedong Gincu Industri Rumah Tangga Libna Food per siklus produksi dapat dilihat pada Tabel 7 sebagai berikut :

Tabel 7.Analisis output,input, dan harga pada nilai Tambah pengolahan kerupuk mangga

\begin{tabular}{llr}
\hline & \multicolumn{1}{c}{ Variabel } & Nilai 250 Gram \\
\hline I. & Output, Input dan Harga & 55 \\
1 & Output $($ Kemasan/Siklus Produksi) $[(1)]$ & 10 \\
2 & Input $(\mathrm{Kg} /$ Siklus Produksi) $[(2)]$ & 4 \\
3 & Tenaga Kerja (HOK/Siklus Produksi) $[(3)]$ & 5,50 \\
4 & Faktor Konversi [(4)=(1)/(2)] & 0,40 \\
5 & Koefisien Tenaga Kerja(HOK/Kg) $[(5)=(3) /(2)]$ & $5.000,00$ \\
6 & Harga Produk (Rp/Kemasan) [(6)] & $6.667,00$ \\
\hline 7 & Upah Rata-Rata Tenaga Kerja (Rp/HOK) $[(7)]$ & \\
\hline
\end{tabular}

Tabel 8. Analisis penerimaan keuntungan pada nilai Tambah pengolahan kerupuk mangga

\begin{tabular}{llr}
\hline II. & Penerimaan dan Keuntungan & \\
\hline 8 & Harga Input Bahan Baku (Rp/Kg) $[(8)]$ & $10.000,00$ \\
9 & Sumbangan Input Lain (Rp/Kemasan) $[(9)]$ & $3.601,00$ \\
10 & Nilai Produk $(\mathrm{Rp} / \mathrm{Kg})[(10)=(4) \times(6)]$ & $27.500,00$ \\
11 & a.Nilai Tambah $(\mathrm{Rp} / \mathrm{Kg})[(11 \mathrm{a})=(10)-(9)-(8)]$ & $13.899,00$ \\
& b.Rasio Nilai Tambah $(\%)$ & 50,54 \\
& {$[(11 \mathrm{~b})=(11 \mathrm{la}) /(10) \times 100 \%]$} & \\
12 & a.Imbalan Tenaga Kerja $(\mathrm{Rp} / \mathrm{Kg})$ & $2.666,80$
\end{tabular}


$[(12 a)=(5) \times(7)]$

b. Bagian Tenaga Kerja (\%)

$[(12 b)=(12 a) /(11 a) \times 100 \%$

b.Tingkat Keuntungan (\%)

80,81

$[(13 b)=(13 a) /(11 a) \times 100 \%]$

Tabel 9.Analisis balas jasa faktor produksi pada nilai Tambah pengolahan kerupuk mangga

\begin{tabular}{llc}
\hline III & Balas Jasa Faktor Produksi & \\
\hline 14 & Marjin $[(14)=(10)-(8)]$ & $17.500,00$ \\
& Pendapatan Tenaga Kerja (\%) & 15,24 \\
& {$[(15)=(12 \mathrm{a}) /(14) \times 100 \%$} & \\
& Sumbangan Input Lain \\
& {$[(16)=(9) /(14) \times 100 \%$} \\
& Keuntungan perusahaan $(\%)$ & 20,58 \\
& {$[(17)=(13 \mathrm{a}) /(14) \times 100 \%$} & 64,18 \\
\hline
\end{tabular}

Berdasarkan hasil analisis nilai tambah pengolahan Kerupuk mangga di Industri Rumah Tangga per siklus produksi dapat diuraikan sebagai berikut :

1. Faktor konversi menunjukkan keterkaitan dengan besarnya jumlah produksi. Hasil perhitungan menunjukkan faktor konversi dari buah mangga menjadi kerupuk mangga pada kemasan 250 gram yaitu sebesar 5,50. hasil tersebut diperoleh dari bahan baku sebanyak 10kg buah mangga dengan menghasilkan 55 kemasan.

2. Koefisien tenaga kerja adalah perbandingan antara input tenaga kerja dengan input bahan baku. Koefisien tenaga kerja ini memiliki nilai 0,40 dari pengolahan kerupuk mangga ukuran 250 gram.

3. Sumbangan input lain adalah biaya yang dikeluarkan selain bahan baku dan biaya tenaga kerja untuk mengolah satu kemasan bahan baku. Sumbangan input lain diperoleh dari penjumlahan biaya bersama (selain biaya bahan baku dan biaya tenaga kerja) dibagi jumlah bahan baku yang digunakan. Sumbangan input lain untuk kemasan 250 gram. Sebesar Rp.3.601.

4. Nilai produk untuk ukuran 250 gram sebesar Rp. 25.000. Nilai ini merupakan perkalian antara faktor konversi dengan harga produk, nilai ini menunjukkan besarnya nilai dari produk yang dihasilkan dari pengolahan satu kemasan bahan baku.

5. Nilai tambah diperoleh dari selisih antara nilai produk dengan harga bahan baku serta sumbangan input lain. Nilai tambah yang diperoleh untuk kemasan 250 gram sebesar Rp. 13.899. dengan nilai rasio sebesar 50,54\%.

6. Imbalan tenaga kerja diperoleh dari perkalian antara koefisien tenaga kerja dengan upah tenaga kerja yaitu dengan perolehan masing-masing sebesar Rp.2.666 untuk kemasan 250 gram.

7. Keuntungan merupakan selisih antara nilai tambah dengan imbalan tenaga kerja. Keuntungan yang diperoleh dalam pengolahan kerupuk mangga mangga dengan kemasan 250 gram sebesar Rp. 11.232. 
8. Marjin merupakan perhitungan laba (keuntungan) sebagai perbandingan terhadap penjualan bersih dan modal perusahaan. Perhitungan marjin diperoleh dari nilai produk dikurangi harga input bahan baku. Marjin yang diperoleh dari pengolahan buah mangga menjadi kerupuk mangga per tiap kemasan ukuran 250 gram sebesar Rp 17.500.

\section{IV.SIMPULAN DAN SARAN}

\section{Simpulan}

Berdasarkan hasil analisis yang telah dilakukan pada Industri Rumah Tangga Libna Food mengenai Analisis Nilai Tambah Pengolahan Mangga Gedong Gincu diperoleh simpulan sebagai berikut :

1. Keripik mangga merupakan salah satu olahan makanan yang memiliki tektur renyah dan memiliki cita rasa yang enak sehingga banyak masyarakat yang menyukai olahan keripik tersebut, mulai dari kalangan anak-anak hingga kalangan dewasa. Disamping itu buah mangga segar, mengandung serat alami buah, yang berguna untuk membantu pencernaan makanan dalam usus

2. Besarnya nilai tambah yang diperoleh pada Industri Rumah Tangga pada agroindustri pengolahan buah mangga menjadi kerupuk mangga perkilogramnya pada ukuran kemasan 250 gram adalah Rp. 13.899,00.

3. Besarnya rasio nilai tambah yang dihasilkan oleh Industri Rumah tangga Libna Food di Desa Jatisura Kecamatan Cikedung Kabupaten Indramayu untuk kemasan 250 gram sebesar 50,54 $\%<50 \%(50,54 \%)$, artinya nilai tambah tergolong tinggi.

\section{Saran-saran}

Berdasarkan hasil penelitian dan simpulan maka ada hal-hal yang dapat disarankan antara lain

1. Dengan diketahuinya nilai tambah yang diperoleh dari hasil usaha yang tergolong tinggi pada olahan buah mangga menjadi kerupuk mangga diharapkan Pengusa Lebih berinovasi dalam kemasan agar membuat daya tarik konsumen bertambah maka kemasan harus di buat dan di Desain semenarik mungkin dan untuk meningkatkan Nilai Tambah dari kerupuk mangga ini pengusaha harus meperbanyak jumlah produk.

2. Sebaiknya cara pengolahan kerupuk mangga menerapkan teknologi modern karena lebih efisien baik waktu maupun tenaga. Seperti penggunaan Frezer dan Alat pisau Buah agar pada saat pendingin tidak memerlukan waktu lama dan saat memotong buah bisa lebih cepat jika menggunakan pisau khusus pemotong buah dan mengurangi resiko daging yang ikut terkelupas dengan kulit mangga

3. Bagi pemerintah atau lembaga instansi terkait, diharapkan dapat membantu Industri Rumah Tangga untuk meminjamkan modal dan membantu cara pemasaran menggunakan media sosial agar dapat menjual produk kerupuk mangga langsung ke konsumen.

\section{Ucapan Terima Kasih}

Ucapan Terimaksih saya ucapkan kepada Fakultas Pertanian dan LPPM UNWIR yang telah membantu dalam penelitian ini Sehingga penelitian ini dapat terlaksana dengan baik.

\section{DAFTAR PUSTAKA}

Badan Pusat Statistik (BPS) Indramayu. Indramayu Dalam Angka 2017. Indramayu.

Badan Pusat Statistik (BPS) Indramayu. Cikedung Dalam Angka 2017. Indramayu.

Billah M. Tassim, MSc. 2014. Outlok Komoditi Mangga. Pusat Data dan Sistem Informasi Pertanian Sekretariat Jenderal Kementerian Pertanian.

Dinas Pertanian Kabupaten Indramayu. 2016. Presentase Varietas Mangga Di Indramayu. 
Djuwari. 1994. Aspek-aspek Ekonomi Usaha Tani. Program Pasca Sarjana. UGM. Yogyakarta.

Downey David W, Dan Erickson P. Steven. 1987. Edisi Kedua, Manajemen Agribisnis. Penerbit Erlangga.

Gasperz, V. 1999. Ekonomi Manajerial Pembuatan Keputusan Bisnis. PT Gramedia. Jakarta

Handayani Rita. 2012. Keragaman Mangga Cengkir di Kabupaten Indramayu. Fakultas Matematika dan Ilmu Pengetahuan Alam. IPB. Bogor.

Hardjanto, W. 1993. Bahan Kuliah Manajemen Agribisnis. Jurusan Ilmu-ilmu Sosial Ekonomi Pertanian. Fakultas Pertanian. IPB. Bogor.

Hayami, Y., at all. 1987. Agricultural Marketing and Processing in Upland Java, A prespective From a Sunda Village. Bogor: CGPRT Centre.

Hicks, P.A. 1995. An Overview of issues and Strategies in The Devolopment of Food Processing Industries In Asia and The Pacific, APO Symposium, 28 September-5 Oktober. Tokyo.

Lipsey, G. R., Peter, O. S. dan Douglas, D. P. 1990. Pengantar Mikroekonomi 1 Jilid I. Diterjemahkan oleh Jaka, A. W dan Kirbrandoko. Erlangga. Jakarta

Makki, M. F. et al. 2001. Nilai Tambah Agroindustri pada Sistem Agribisnis Kedelai di Kalimantan Selatan. Dalam jurnal Agro Ekonomika. Vol. VI. No. 1. Juli 2001.

Medina, J. De La Cruz., H. S. Garcia. 2002. Mango : Post-harvest Operation. Food and Agriculture Organization of United Nation (FAO). Veracruz.

Nazir M,2011. Metode Penelitian. Galia Indonesia. Bogor

Oktavianto yoga. et al. 2012. Karakteristik Tanaman Mangga (Mangiferaindica, L.) Cabtek Ireng, Jempol di Desa Tiron Kecamatan Banyakan Kabupaten Kediri. Fakultas Pertanian Universitas Brawijaya. Kediri.

Pracaya. 2006. Bertanam Mangga. Penerbit Swadaya, anggot Ikapi. Bogor.

Purba, R. 1986. Manajemen Manunggal Bagi Wiraswasta. Pustaka Dian. Jakarta.

Pusat Data Dan Sistem Informasi Pertanian Sekretariat Jendral. 2014. Outlook Komoditi Mangga. Kementrian Pertanian.

Pusat Kajian Buah Tropika. 2000. Riset Unggulan Strategis Nasional Pengembangan BuahBuahan Unggulan Indonesia. Pusat Kajian Buah Tropika. Institut Pertanian Bogor.

Rahman Syamsul. 2015. Analisis Nilai Tambah Agroindustri Chips Jagung(Analysis of Added Value of Corn Chips Agro-industry). Jurnal. Fakultas Pertanian, Universitas Islam Makassar.

Ravianto. 1988. Dasar-Dasar Produktivitas. Karunika. Jakarta.

Rosadi Imron. 2017. Analisis Nilai Tambah Agroindustri Dodol Mangga (Mangifera indica L.) Skripsi. Fakultas Pertanian Universitas Wiralodra Indramayu.

Soeharjono. 2001. Konsep dan Ruang Lingkup Agroindustri. Kumpulan Makalah Agribisnis Jurusan Sosial Ekonomi Pertanian. IPB. Bogor.

Soekartawi. 1995. Analisis Usahatani. UI-Press, Jakarta. 1996. Agroindustri. Raja Grafindo Persada. Jakarta.

1999. Agribisnis Teori dan Aplikasi. PT. Raja Grafindo Persada. Jakarta.

2000. Pengantar Agroindustri. PT. Raja Grafindo Persada : Jakarta.

2001. Pengantar Agroindustri. Perpustakaan Digital. Universitas Negeri Malang Koleksi Buku. PT. Raja Grafindo Persada. Jakarta.

Standar Industri Indonesia. 1985. SII Mutu dan Uji Kerupuk. Departemen Perindustrian Republik Indonesia Bogor : Fakultas Pertanian Institut Pertanian Bogor. 
Sugiyono. 2010. Metode Penelitian Pendidikan. Bandung.

Suhendar, Hary., 2002. Analisis Nilai Tambah dan Strategi Pengembangan Industri Kecil Tahu Sumedang (Studi Kasus di Bogor, Jawa Barat). Makalah Penelitian Jurusan Ilmu-ilmu Sosial Ekonomi Pertanian Fakultas Pertanian IPB. Bogor.

Suryana, A. 1990. Diversifikasi Pertanian dalam Proses Mempercepat Laju Pembangunan Nasional. Pustaka Sinar Harapan. Jakarta.

Sutawi.2002. Manajemen Agribisnis. Edisi pertama. Bayu Media \& UMM Press.Malang.

Tarigan, R. 2004. Ekonomi Regional. Bumi Aksara. Jakarta.

Valentina Oxy. 2009. Analisis Milai Tambah Ubi Kayu Sebagai Bahan Baku Keripik Singkong Di Kabupaten (Kasus Pada KUB Wanita Tani Makmur). Skripsi. Fakultas Pertanian. Universitas Sebelas Maret. Surakarta.

Wijandi,S. B.Djatmiko. D,Mudtadi. Setijahartini. H.Syarif dan Kusupiyanti.1975 Pengolhan Kerupuk Sidoarjo 